\title{
Risk Stratification in Upper Gastrointestinal Bleeding: A Measure of Safety and Efficiency in Emergency Care
}

\author{
Pedro Costa-Moreira ${ }^{a, b}$ Guilherme Macedo ${ }^{a, b}$ \\ ${ }^{a}$ Gastroenterology Department, Centro Hospitalar Universitário São João, Porto, Portugal; b Faculty of Medicine, \\ University of Porto, Porto, Portugal
}

Keywords

Gastrointestinal bleeding · Risk stratification scores .

Emergency in gastroenterology

\section{Estratificação do Risco em Hemorragia Digestiva Alta: Uma Medida de Segurança e Eficiência dos Cuidados Urgentes}

\section{Palavras Chave}

Hemorragia digestiva · Scores de estratificação de risco . Urgências em gastrenterologia

Acute upper gastrointestinal bleeding (UGIB) is commonly encountered in emergency departments. Despite remarkable advancements in medical treatments and endoscopic interventions, it remains a potentially lifethreatening event. The mortality rate among patients with acute UGIB can range from 2 to $15 \%$ [1-3]. This disease also presents with high morbidity, being one of the leading causes of hospitalization due to digestive disorders [4], and remains a significant and rising economic burden [5].

karger@karger.com www.karger.com/pjg

Karger $\stackrel{\text { ' }}{5}$

GOPEN ACCESS
(C) 2020 Sociedade Portuguesa de Gastrenterologia Published by S. Karger AG, Basel

This is an Open Access article licensed under the Creative Commons Attribution-NonCommercial-4.0 International License (CC BY-NC) (http://www.karger.com/Services/OpenAccessLicense), applicable to the online version of the article only. Usage and distribution for commercial purposes requires written permission.
Given the increasing burden and number of UGIB cases, accurate risk stratification at initial presentation is critical to efficient resource management. The goal of the evaluation is to assess the severity of the bleed, where patients with GIB identified as being at low risk of a hospital-based intervention can be discharged from the emergency department to outpatient care. On the other hand, high-risk patients can be triaged for timely performance of endoscopy following guideline recommendations [4].

The two most widely used scores are the Rockall score (RS) and the Glasgow-Blatchford score (GBS). The GBS is one of the best-studied and validated scores [6], and clinical guidelines strongly recommend its use for preendoscopic risk stratification based on evidence from cohort studies [7]. Since the derivation of the RS in the 1990s, there have been important developments in the management of UGIB, including the pharmacologic treatment of bleeding, advances in endoscopic techniques, and evolving evidence for the use of transfusion. Therefore, it is currently unclear whether the full RS or the pre-endoscopic RS remains valid almost two decades after their derivation [8].

Although the use of these risk stratification systems is strongly encouraged in current guidelines, a 2014 nationwide study of 1,402 emergency physicians, internists, and 
gastroenterologists in the USA revealed that only 53\% had ever heard of a UGIB risk score and only $30 \%$ had ever used it [9]. Possible barriers to adherence include lack of knowledge because the literature on risk assessment in UGIB is primarily published in gastroenterology and endoscopy journals, as well as difficulty in recalling risk [10].

Also, the endoscopy timing for patients with acute nonvariceal UGIB is controversial. According to international consensus recommendations on nonvariceal UGIB, early endoscopy within $24 \mathrm{~h}$ is recommended for most patients with acute nonvariceal UGIB ("urgent endoscopy") $[7,11,12]$. However, some studies have examined outcomes of endoscopy performed within 6-12 h (or even earlier - "emergent endoscopy") [10]. Previous trials globally have shown that no differences in clinical outcome were found between the two groups, even though the "emergent endoscopy" group had more high-risk endoscopic lesions [10]. The more frequent endoscopic treatment, however, did not translate into a lower incidence of further bleeding or fewer deaths. This is a complex outcome to measure; for example, in patients with a longer period until endoscopy and longer duration of acid suppression - administered at the beginning of clinical observation - there is probably a reduced number of ulcers with active bleeding or major stigmata of bleeding [13].

Because many hospitals do not have the capability to provide endoscopy $24 \mathrm{~h}$ a day and 7 days a week, it will be important to restrict the performance of urgent endoscopy to selected patients. Many studies have defined high-risk patients as those with a GBS $>12$, or by using other clinical parameters $[14,15]$. This aspect highlights the need for clinical studies (combined with a health economy analysis) that aim to investigate the performance of prediction scores in a large pooled data set of patients with UGIB, adapted to national/regional circumstances. In accordance with this, Maia et al. [16] reported the ability of the GBS and RS to predict various clinical outcomes and possible cutoff points to identify low- and high-risk patients in the setting of referral/metropolitan gastroenterology emergency departments. The authors showed that the RS and the pre-endoscopic RS were effective at predicting mortality, and that the GBS was better at predicting transfusion requirement. Also, the authors showed no adverse outcomes when the GBS was $\leq 3$, suggesting that hospital transfer may be reconsidered if the GBS is 3 points or less.

The prioritization of urgent endoscopy has another implication. There is an ongoing controversy about the existence of a "weekend effect," whereby mortality from UGIB may be higher after regular working hours than at other times. Some authors postulate that this effect may be due to a patient selection bias (the sickest present at any time, including after hours) or decreased resources, including delays to endoscopy and other treatment [1719].

On the other hand, determining the most important clinical outcome for patients with UGIB is not straightforward. Initially, death was prioritized, and longitudinal population studies have shown a reduction in case fatality rates over the past two decades [8]. Furthermore, most patients die from a comorbidity rather than from the bleeding. Predicting the need for hospital-based intervention also has clinical relevance (endoscopic or radiologic therapy, surgery, or transfusion), and studies on outcome definition may be needed.

In conclusion, an ideal risk score would be a pre-endoscopic tool that allows the early identification of patients at high risk of a negative outcome, as well as low-risk patients who can be discharged without requiring inpatient procedures, thereby improving both the safety and the efficiency of care. Furthermore, in the future, automation will likely redefine risk assessment. The possibility of dashboard recording of pre-endoscopic scores embedded in the electronic medical records at a patient's presentation, as well as the creation of electronic alerts that can trigger low- and high-risk gastrointestinal bleeding order sets, can be of value guiding physicians on evidence-based practice.

\section{Conflict of Interest Statement}

All authors disclosed no personal conflicts of interest or financial relationships relevant to this publication.

\section{Funding Sources}

There is no funding declaration.

\section{Author Contributions}

P. Costa-Moreira: manuscript concept and design, literature review, and draft of the manuscript. G. Macedo: critical revision of the manuscript. Both authors revised the manuscript and approved the final version. 


\section{References}

1 Liu NJ, Lee CS, Tang JH, Cheng HT, Chu YY, Sung KF, et al. Outcomes of bleeding peptic ulcers: a prospective study. J Gastroenterol Hepatol. 2008 Aug;23(8 Pt 2):e340-7.

2 Crooks C, Card T, West J. Reductions in 28day mortality following hospital admission for upper gastrointestinal hemorrhage. Gastroenterology. 2011 Jul;141(1):62-70.

3 Lanas A, Carrera-Lasfuentes P, García-Rodríguez LA, García S, Arroyo-Villarino MT, Ponce J, et al. Outcomes of peptic ulcer bleeding following treatment with proton pump inhibitors in routine clinical practice: $935 \mathrm{pa}-$ tients with high- or low-risk stigmata. Scand J Gastroenterol. 2014 Oct;49(10):1181-90.

4 Sengupta N. Integrating Gastrointestinal Bleeding Risk Scores into Clinical Practice. Am J Gastroenterol. 2019 Nov; 114(11):1699703.

5 Abougergi MS, Travis AC, Saltzman JR. The in-hospital mortality rate for upper GI hemorrhage has decreased over 2 decades in the United States: a nationwide analysis. Gastrointest Endosc. 2015 Apr;81(4):882-8.e1.

6 Blatchford O, Murray WR, Blatchford M. A risk score to predict need for treatment for upper-gastrointestinal haemorrhage. Lancet. 2000 Oct;356(9238):1318-21.

7 Gralnek IM, Dumonceau JM, Kuipers EJ, Lanas A, Sanders DS, Kurien M, et al. Diagnosis and management of nonvariceal upper gastrointestinal hemorrhage: European Society of Gastrointestinal Endoscopy (ESGE) Guideline. Endoscopy. 2015 Oct;47(10):a146.
8 Oakland K, Kahan BC, Guizzetti L, Martel M, Bryant RV, Brahmania M, et al. Development, Validation, and Comparative Assessment of an International Scoring System to Determine Risk of Upper Gastrointestinal Bleeding. Clin Gastroenterol Hepatol. 2019 May; 17(6):1121-9.e2.

9 Liang PS, Saltzman JR. A national survey on the initial management of upper gastrointestinal bleeding. J Clin Gastroenterol. 2014 Nov-Dec;48(10):e93-8.

10 Cai JX, Saltzman JR. Initial Assessment, Risk Stratification, and Early Management of Acute Nonvariceal Upper Gastrointestinal Hemorrhage. Gastrointest Endosc Clin N Am. 2018 Jul;28(3):261-75.

11 Barkun AN, Bardou M, Kuipers EJ, Sung J, Hunt RH, Martel M, et al.; International Consensus Upper Gastrointestinal Bleeding Conference Group. International consensus recommendations on the management of patients with nonvariceal upper gastrointestinal bleeding. Ann Intern Med. 2010 Jan;152(2): 101-13.

12 Laine L, Jensen DM. Management of patients with ulcer bleeding. Am J Gastroenterol. 2012 Mar; 107(3):345-60; quiz 361.

13 Siau K, Ishaq S. Timing of Endoscopy for Acute Upper Gastrointestinal Bleeding. N Engl J Med. 2020 Jul;383(4):e19.
14 Tai CM, Huang SP, Wang HP, Lee TC, Chang $\mathrm{CY}, \mathrm{Tu} \mathrm{CH}$, et al. High-risk ED patients with nonvariceal upper gastrointestinal hemorrhage undergoing emergency or urgent endoscopy: a retrospective analysis. Am J Emerg Med. 2007 Mar;25(3):273-8

15 Lim LG, Ho KY, Chan YH, Teoh PL, Khor CJ, Lim LL, et al. Urgent endoscopy is associated with lower mortality in high-risk but not lowrisk nonvariceal upper gastrointestinal bleeding. Endoscopy. 2011 Apr;43(4):300-6.

16 Maia S, Falcão D, Silva J, Pedroto I. The clinical impact of Rockall and Glasgow-Blatchford scores in nonvariceal upper gastrointestinal bleeding. GE Port J Gastroenterol. 2020 [Online ahead of print].

17 Soncini M, Chilovi F, Triossi O, Leo P. Weekend effect in non-variceal upper gastrointestinal bleeding: data from nine italian gastrointestinal units. Am J Gastroenterol. 2012 Apr;107(4):635-6.

18 Tufegdzic M, Panic N, Boccia S, Malerba S, Bulajic M, La Vecchia C, et al. The weekend effect in patients hospitalized for upper gastrointestinal bleeding: a single-center 10-year experience. Eur J Gastroenterol Hepatol. 2014 Jul;26(7):715-20.

19 Ahmed A, Armstrong M, Robertson I, Morris AJ, Blatchford O, Stanley AJ. Upper gastrointestinal bleeding in Scotland 2000-2010: improved outcomes but a significant weekend effect. World J Gastroenterol. 2015 Oct; 21(38):10890-7. 